\title{
MECHANICAL PROPERTIES OF QUENCH-HARDENED, MARTEM- PERED AND TEMPERED ASTM A 128 GRADE B-4 STEEL
}

\author{
S. A. Ibitoye ${ }^{1}$ J. O. Olawale ${ }^{2}$ and M. D. Shittu ${ }^{3}$ \\ ${ }^{1,2,3}$ Department of Materials Science and Engineering \\ Obafemi Awolowo University \\ Ile-Ife 220005, Nigeria.
}

\begin{abstract}
This investigation is conducted to assess the influence of some heat treatment procedures on the structure and mechanical properties of cast ASTM A grade B-4 steel to which formation of grain boundary carbides have been a major problem. Some cast ASTM A grade B-4 steel samples were quench-hardened, martempered and tempered. The as-cast and heat-treated samples were thereafter tested for tensile strength, yield strength, impact strength, ductility and hardness. Some of the samples were also prepared for metallographic examination and their microstructures were studied. It was observed that in all cases, the microstructures were mainly austenite matrix with or without carbides at the grain boundaries and in the austenitic grains depending on the heattreatment adopted. The measured mechanical properties varied and were greatly dependent on the presence or absence of carbides either at the grain boundaries or at both the grain boundaries and in the grains of austenite matrix. Two of the heat treatment procedures were found to be appropriate as post-casting processes suitable for ASTM A 128 grade B-4 steel components designed to function under a condition in which impact strength and hardness are simultaneously required.
\end{abstract}

Keywords: austenitic manganese steel, heat treatment, mechanical properties, grain boundaries, carbides

\section{INTRODUCTION}

Sir Robert Hadfield invented the original austenitic manganese steel, containing about $1.2 \%$ $\mathrm{C}$ and $12 \% \mathrm{Mn}$ in 1882 (Perry and Green, 1997). Hadfield's steel was unique in that it combined high toughness and ductility with high work-hardening capacity, usually good resistance to wear and possession of slow crack propagation rates (Subramanyan et al, 1990; Avery, 1995; Rajan et al, 1999; Smith et al, 2004). These non-magnetic steels harden in use, or prior to service can be surface-hardened by mechanical or explosive means to as high as 450 BHN (Peter, 1980). Consequently, it rapidly gained acceptance as a very useful engineering material in comparison with other potential competitive materials. Hadfield's austenitic manganese steel performs best when its grain boundaries are free of carbides. Works have been done to modify the original Hadfield steel by the addition of other alloying elements (Rittel et al, 1989; Klueh, R. L. and Maziasz, 
1990; Bayraktar et al, 1994; Miyahara et al, 1994; Takahashia et al, 1998; He, et al, 2002; Kuc et al, 2006; Zhang et al, 1998), by varying its composition (Zhang et al, 1998; García, 2005; Gavriljuk et al, 2006) or subjecting it to various treatments (Pelletier et al, 1995; John and Cornog, 1997; Owen and Grujicic, 1998; Zhang et al, 2007; Wang et al, 2007) in order to meet different engineering application. Improvement on the mechanical properties of austenitic manganese steel over the years has not been exhausted. In all cases austenitic manganese steels are generally useful engineering materials.

However, in as-cast condition it is difficult to obtain an austenitic structure in austenitic manganese steel that is sufficiently free of grain boundary carbides. The presence of grain boundary carbides is detrimental to strength and ductility. Although carbides formed in the castings that are cooled slowly in the moulds, they form in practically all as-cast grades of austenitic manganese steels containing more than $1.0 \% \mathrm{C}$, regardless of mould cooling rates (Subramanyan et al, 1990). The final microsture in most as-cast grade is not fully austenitic but contains carbide precipitate and pearlite in an austenite grain boundary and matrix (Wiscers, 1980). The presence of these carbides causes the embrittlement of the material and in essence affects its application as engineering material that has resistance to impact and abrasion wear.

The embrittlement of ASTM A 128 grade B-4 (Table 1) is major setback to its use in as-cast condition for the production of products for which toughness at reasonable level and high hardness is simultaneously required. Though works have been done on different austenitic manganese steels over the years, the response of ASTM A 128 grade B-4 (Table 1) to various heat-treatment procedures with respect to its mechanical properties has not been reported. Thus in this work, a grade of an austenitic manganese steel, ASTM A 128 grade B-4 (Table 1) is cast and subjected to different heat treatment procedures in order to evaluate their influence on the structure and some mechanical properties of this alloy.

\section{EXPERIMENTAL PROCEDURE \\ Sample Preparation}

Austenitic manganese steel was prepared in accordance with ASTM Standard (ASTM A128/A128M-93, 2007) to conform to ASTM A 128 grade B-4 (Table 1) steel. Cylindrical rod with a diameter of $20 \mathrm{~mm}$ and $500 \mathrm{~mm}$ length sample was cast from the prepared steel. From the rod, some standard test pieces were machined to diameter $11.4 \mathrm{~mm}$ by $75 \mathrm{~mm}$ length and notched to $3.3 \mathrm{~mm}$ and $45^{\circ}$ included angles for impact test. Similarly, standard test specimens were prepared in accordance with British Standard for proportional round testpieces for tensile strength (BSI BS EN 100021, 2001). The impact strength, tensile strength and hardness were determined and the proof stress, percent elongation and reduction in area at fracture were also determined.

\section{Heat Treatment}

Sixty test samples comprising twenty-five specimens for tensile strength, twenty-five for impact, five each for hardness and micro examination were rapidly heated inside a Bogie Hearth heat treatment furnace to $340^{\circ} \mathrm{C}$. This was followed by slow heating at the rate of $100^{\circ} \mathrm{C}$ per hour to $1040^{\circ} \mathrm{C}$ and held at this temperature for about $1.5 \mathrm{hr}$ to homogenize the structure (Prabhudev, 1988). They were thereafter subjected to various treatments as detailed below:

Water Quenching: Forty-eight of the samples were removed and then quenched in agitated water for hardening and tempering heat treatment operations. Out of these twelve were used for mechanical testing and micro examination in quench hardened conditions, and thirty-six were used for tempering heat treatment.

Martempering: The remaining twelve samples were quenched in a molten salt-bath maintained at $250^{\circ} \mathrm{C}$. They were soaked in the bath at this temperature for about $1 \mathrm{hr}$ to ensure uniformity of temperature for all the samples at $250^{\circ} \mathrm{C}$. The

108 Journal of Science and Technology, Vol. 29, No. 2, Aug., 2009 
samples were then taken out of the bath and allowed to cool in air.

High Temperature Tempering: Twelve of the water-quenched samples were slowly heated to $550{ }^{\circ} \mathrm{C}$ at the rate of $50{ }^{\circ} \mathrm{C}$ per hour, holding at this temperature for $1 \mathrm{hr}$ and thereafter cooled in air to ambient temperature.

Medium Temperature Tempering: Another twelve of the water-quenched samples were slowly heated to $450^{\circ} \mathrm{C}$ at rate of $50^{\circ} \mathrm{C}$ per hour, holding them at this temperature for $1 \mathrm{hr}$ and followed by air-cooling to ambient temperature.

Low Temperature Tempering: The remaining twelve of the water-quenched samples were slowly heated to $250{ }^{\circ} \mathrm{C}$ at rate of $50{ }^{\circ} \mathrm{C}$ per hour, holding them at this temperature for $1 \mathrm{hr}$ and followed by cooling in air to ambient temperature.

\section{Mechanical Testing}

The Brinell hardness tester was employed for determining the hardness of the samples. A 10 $\mathrm{mm}$ hardened standard steel ball under a consistent load of $3000 \mathrm{~kg}$ was pressed into the surface of the specimens to be tested. Having removed the load, indentation diameter left on the surface of the specimen was measured and the hardness value determined using Eq. (1).

The tensile test was performed using Universal Tensile Testing Machine. The values of proof stresses were read directly from the graph of stress strain curve and tensile strength determined using Eq. (2). The percent elongation and reduction in area were calculated in accordance to Eq. (3) and (4) respectively.

The impact strength in this study was measured by Izod impact test method (Rajan et al, 1999) using universal impact testing machine.

The Brinell Hardness Number (BHN) is the ratio of an applied load to area of indentation produced by spherical steel ball pressed into a specimen under the action of the applied load and calculated thus:

$$
H B=\frac{P}{(\pi D / 2)\left(D-\sqrt{\left(D^{2}-d^{2}\right)}\right)}
$$

Where $\mathrm{HB}=$ Brinell hardness number, in $\mathrm{kg} /$ $\mathrm{mm}^{2} ; \mathrm{P}=$ Applied load in $\mathrm{kg}, \mathrm{D}=$ Diameter of ball in $\mathrm{mm}$ and $\mathrm{d}=$ Diameter of indent in $\mathrm{mm}$.

The tensile strength, also known as ultimate tensile strength $\left(\sigma_{U T S}\right)$ is the maximum stress that the material can withstand before failure and it is calculated by an expression:

$$
\sigma_{U T S}=\frac{F_{\max }}{A_{o}}
$$

where $F_{\max }$ and $A_{o}$ is the maximum applied load and initial cross sectional area respectively. From tensile testing, other properties of materials such as yield strength, elongation and reduction in area are also determined. The yield strength is determined as the stress at which plastic deformation (elongation/extension) of the tensile specimen takes place at a constant load.

Percent elongation, $\varepsilon$, is a change in length per unit length of the tensile specimen expressed thus:

$$
\varepsilon=\frac{L_{f}-L_{o}}{L_{o}} \times 100
$$

where $L_{f}$ and $L_{o}$ is the final and initial gauge length of the tensile specimen respectively.

Reduction in area which is often expressed in percentage also computed by equation:

$$
R A=\frac{A_{o}-A_{f}}{A_{o}} \times 100
$$

where $A_{o}$ and $A_{f}$ is the initial and final crosssectional area of the tensile specimen respectively. Reduction in area is independent of the sample gauge length and reflects the local deformation in the necked region. For these reasons, it is considered as a better measure of ductility.

Impact strength is capability of a material to absorb energy without failure under impact loading. In actual service, a component such as crusher jaw is subjected to dynamic loading for which reason; knowledge of tensile strength 
alone is inadequate for use as design parameters.

\section{Micro Examination}

With the help of a hacksaw, samples in the ascast, water quenched, martempered, low tempered, medium tempered and high tempered state were cut for micro examination to a size of $20 \mathrm{~mm}$ diameter by $20 \mathrm{~mm}$ and were mounted on bakelite for easy handling. This was followed by grinding the sample on a grinding wheel using various grades of silicon carbide papers with increasing fineness of 180 $\mathrm{m} \mu, 240 \mathrm{~m} \mu, 320 \mathrm{~m} \mu, 400 \mathrm{~m} \mu, 600 \mathrm{~m} \mu$ and $1200 \mathrm{~m} \mu$. Thereafter, the samples were polished using rotating grinding machine with various grades of Selvyt cloth impregnated with silicon pastes of increasing fineness in the order of $10 \mathrm{~mm}, 6 \mathrm{~mm}$ and $3 \mathrm{~mm}$. The final polishing was carefully carried out on a rotating disc covered with Selvyt cloth sprinkled with $1 \mathrm{~mm}$ diamond paste. It was thereafter etched using $2.5 \%$ natal, rinsed in methanol, re-etched in $15 \%$ $\mathrm{HCl}$, swilled in running water and dried in hot air. The prepared samples were then examined using optical and scanning electron microscopes.

\section{RESULTS}

The results of tensile strength, proof stress, percentage elongation and percentage reduction in area for each of the as-cast and heat-treated samples are presented in Table 2.

The results of micro examination are as shown in the optical micrographs presented in Plates 1 - 7. Plate 1 and 2 shows austenite structure with carbide along the grain boundaries for ascast sample and Plates 3 and 4 show austenite grain boundaries in austenite matrix for waterquenched and martempered respectively. It is noted however, that the austenite grain boundaries in Plate 4 have almost disappeared. Plates 5, 6 and 7 correspond to microstructure of low, medium and high tempered sample respectively showing austenite structure with carbide precipitates along the grain boundaries.

The microstructure in the as-cast condition shows carbides (black constituents) precipitated along austenite grain boundaries and sparsely dispersed in the grains (Plate 1). The concentration of the carbides is clearly revealed in Plate 2 . In water-quenched condition, the microstructure also reveals austenitic grains as presented in Plate 3. The black lines in microstructure are

Table 1: The Chemical Composition of the Prepared ASTM A 128 Grade B-4

\begin{tabular}{lcccc}
\hline Element & $\mathrm{C}$ & $\mathrm{Mn}$ & $\mathrm{Si}$ & $\mathrm{P}$ \\
\hline Composition $(\%)$ & 1.260 & 12.600 & 0.934 & 0.056 \\
\hline
\end{tabular}

Table 2: Mechanical Test Results

\begin{tabular}{lcccccc}
\hline \multicolumn{1}{c}{ Sample } & $\begin{array}{c}\text { Tensile } \\
\text { Strengt } \\
\text { h (MPa) }\end{array}$ & $\begin{array}{c}\text { Proof } \\
\text { Stress } \\
(\mathbf{M P a})\end{array}$ & $\begin{array}{c}\text { Percentage } \\
\text { Elongation } \\
(\boldsymbol{\%})\end{array}$ & $\begin{array}{c}\text { Percentage } \\
\text { Reduction } \\
\text { in Area }(\boldsymbol{\%})\end{array}$ & $\begin{array}{c}\text { Hard- } \\
\text { ness } \\
(\mathbf{H B})\end{array}$ & $\begin{array}{c}\text { Impact } \\
\text { Strength }(\mathbf{J})\end{array}$ \\
\hline As-Cast & 725 & 352 & 37.0 & 33.0 & 215 & 117 \\
Water Quenched & 705 & 345 & 40.0 & 34.5 & 209 & 134 \\
Martempering & 680 & 330 & 45.5 & 37.4 & 201 & 138 \\
Low Tempering & 765 & 359 & 36.0 & 30.0 & 228 & 115 \\
Medium Tempering & 820 & 365 & 32.0 & 28.3 & 241 & 112 \\
High Tempering & 827 & 380 & 31.0 & 27.7 & 245 & 100 \\
\hline
\end{tabular}

110 Journal of Science and Technology, Vol. 29, No. 2, Aug., 2009 


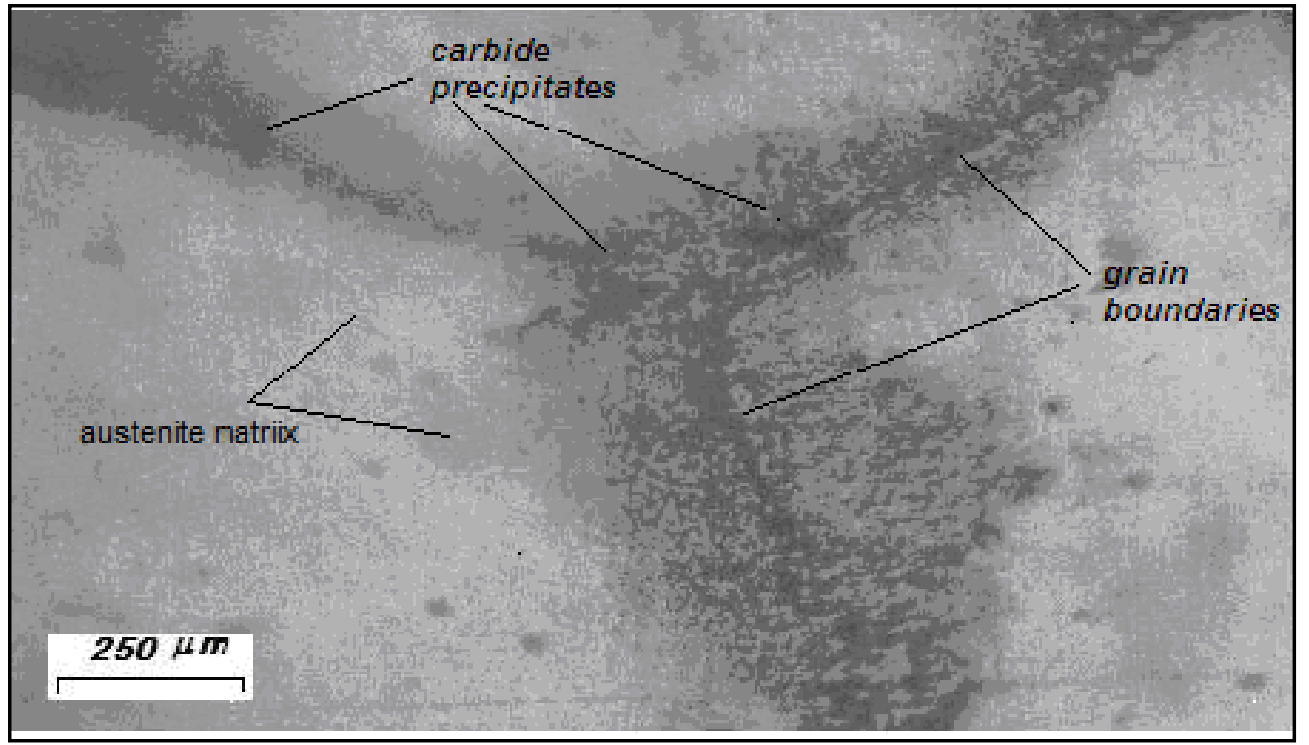

Plate 1: Optical micrograph of the prepared as-cast ASTM A 128 grade B-4 showing collection of carbide precipitates (darkish) concentrated at austenite grain boundaries and sparsely distributed in the austenite matrix

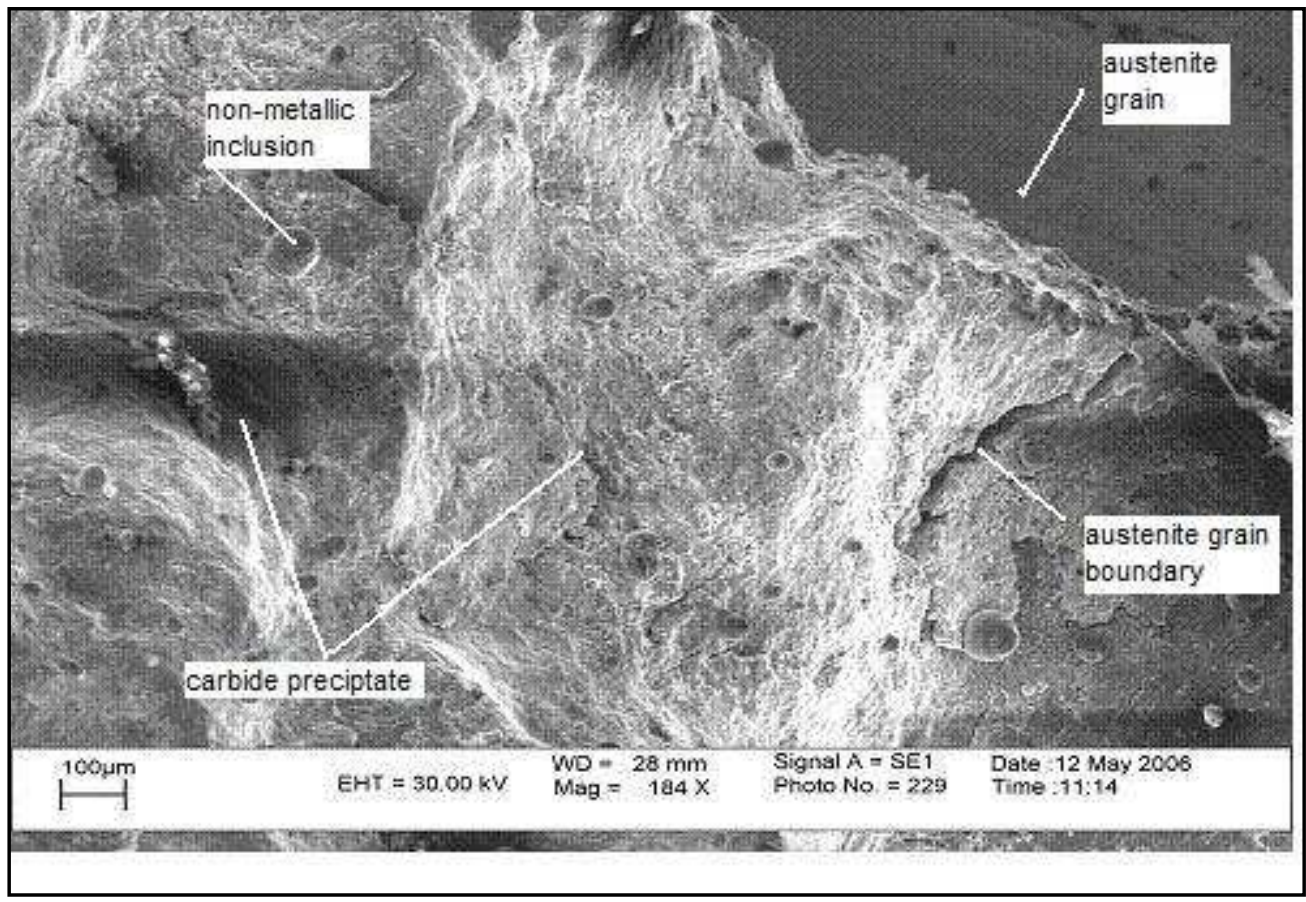

Plate 2: Scanning electron micrograph of as-cast ASTM A 128 grade B-4 prepared showing grain boundary carbide precipitates 
austenite grain boundaries but there are no grain boundary carbides. In martempering condition, the microstructure also reveals austenitic grains (Plate 4) with no grain boundary carbides. The austenite grain boundaries however, have almost disappeared. The very scanty tiny black dots are grain boundary carbide particles that have failed to dissolve during austenizing and large black spots are non-metallic inclusions. In tempering condition, the microstructure reveals austenite grains with precipitated carbide at grain boundaries and in grain as shown in Plate 5 - 7. But the proportion of volume of precipitated carbides increases with increase in tempering temperature.

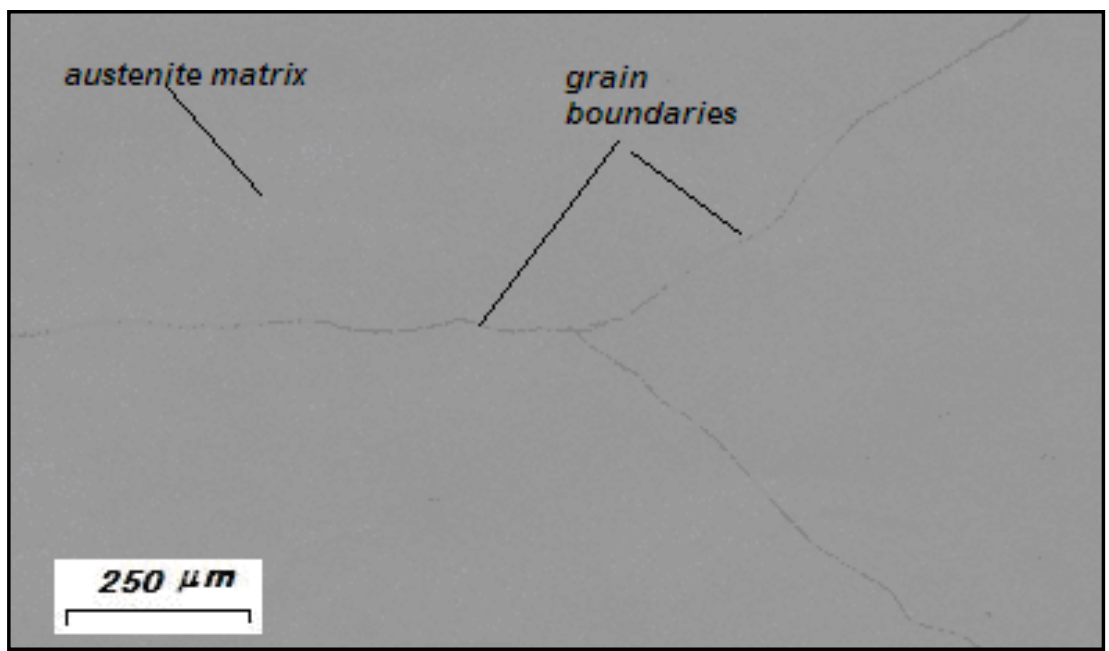

Plate 3: Optical micrograph of sample quenched at $1040{ }^{\circ} \mathrm{C}$ in water showing austenite grain boundaries (lines) in austenite matrix (homogeneous grayish background)

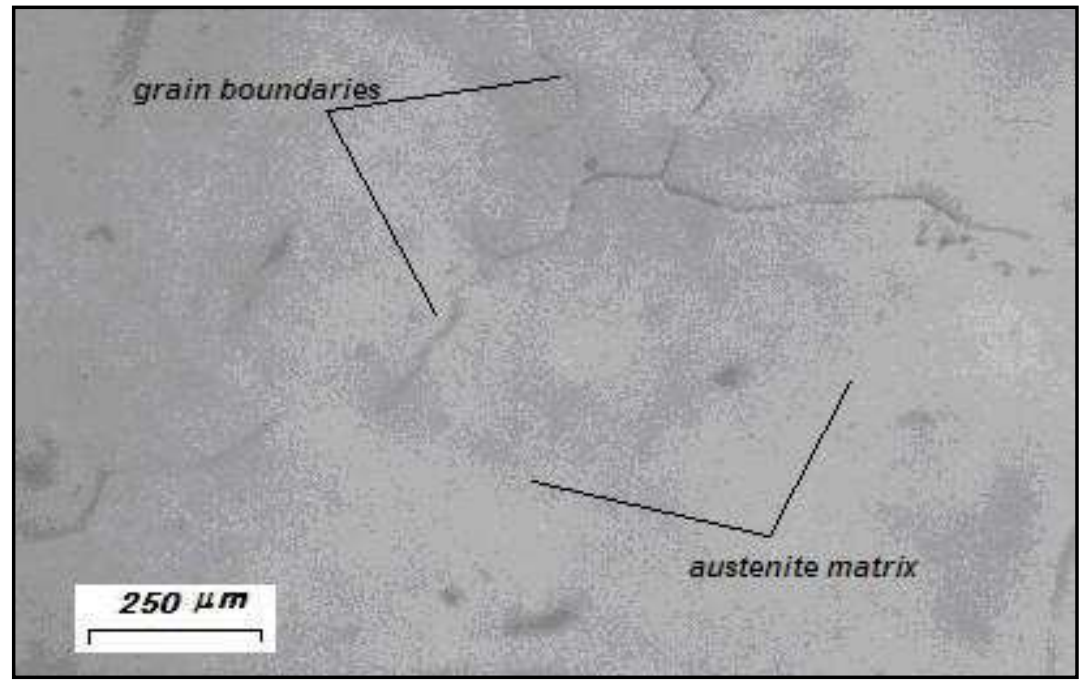

Plate 4: Optical micrograph of martempered sample (heated to $1040^{\circ} \mathrm{C}$ and quenched in salt bath at $250^{\circ} \mathrm{C}$ ) showing grain boundaries (lines) in austenite matrix

112 Journal of Science and Technology, Vol. 29, No. 2, Aug., 2009 


\section{DISCUSSION}

The as-cast and tempered ASTM A 128 grade B-4 steel show high tensile strength, yield strength and hardness but low ductility and toughness (Table 2). In water-quenched and martempered conditions, the steel show higher toughness and ductility with lower tensile strength, proof stress and hardness than as-cast and tempered conditions.

The as-cast steel is characterized with carbides precipitates at the grain boundaries (Plate 1 \& $2)$. The formation of carbides along grain boundaries in as-cast condition is due to development of carbide during the slow cooling in the mould [Perry et al, 1997; Prabhudev, 1988). The rate at which the casting is cooled in the mould is slow and this leads to saturation of

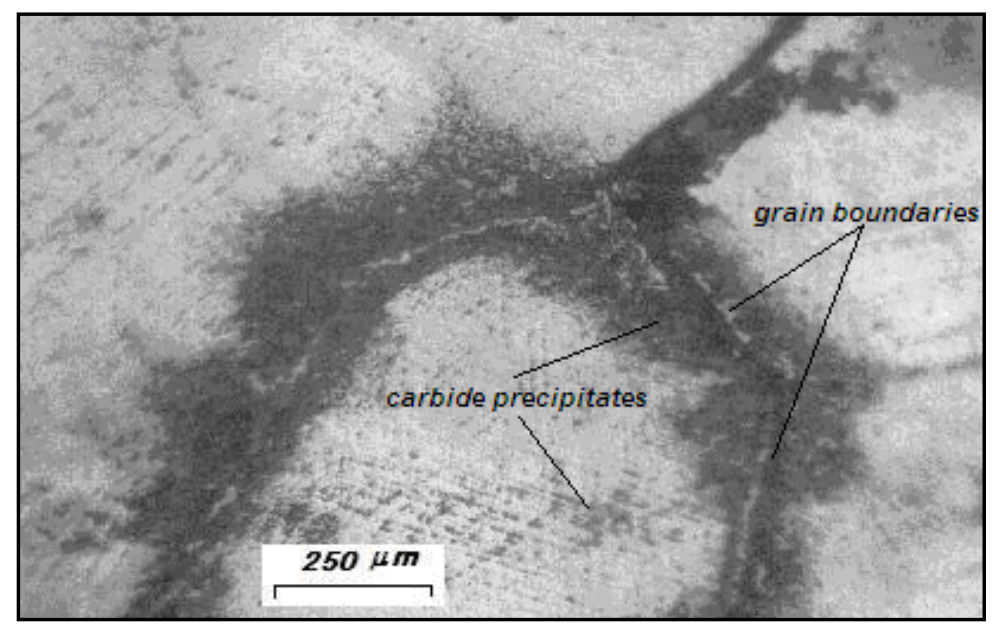

Plate 5: Optical micrograph of low tempered sample (heated to $1040^{\circ} \mathrm{C}$, water-quenched and re-heated to $250^{\circ} \mathrm{C}$ ) showing the precipitated carbide (blackish) at the grain boundaries and in the grain of austenite matrix

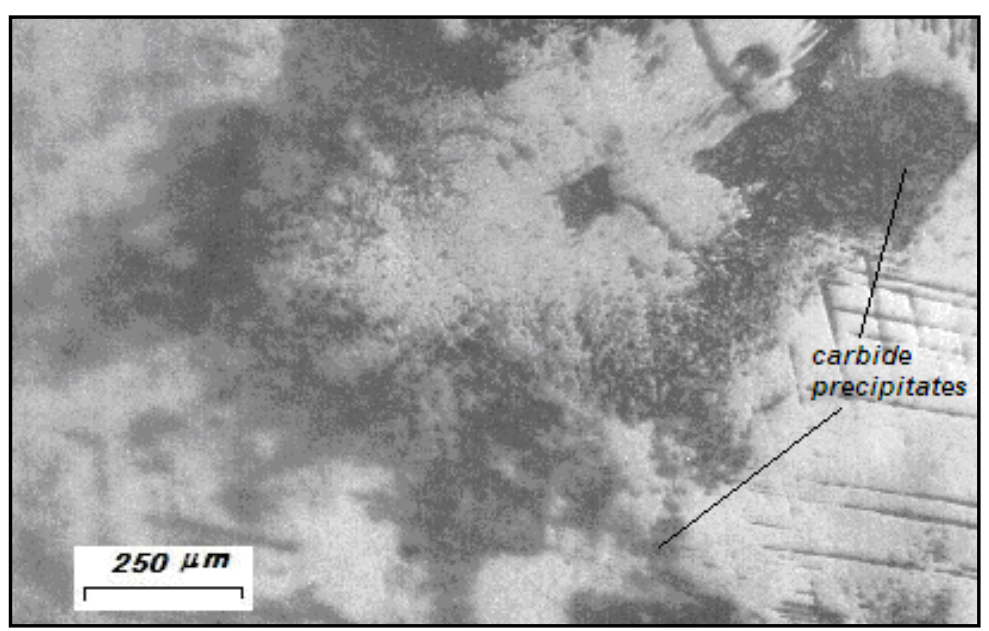

Plate 6: Optical micrograph of medium tempered sample (heated to $1040{ }^{\circ} \mathrm{C}$, water quenched and re-heated to $450^{\circ} \mathrm{C}$ ) showing the precipitated carbide (blackish) at the grain boundaries and in the grain of austenite matrix 


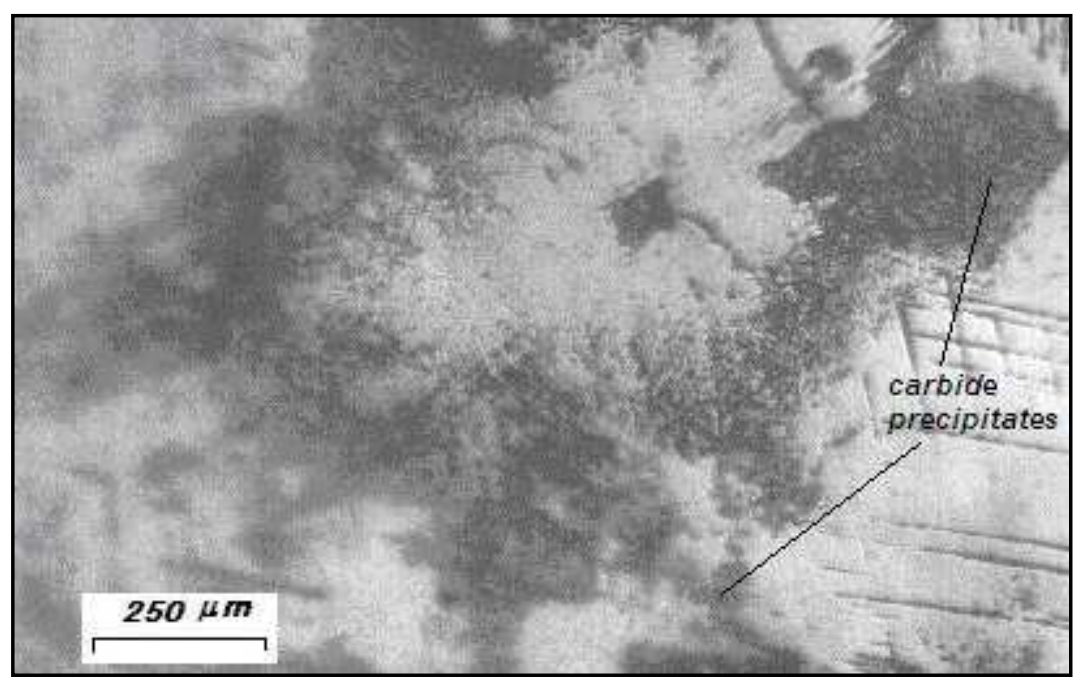

Plate 7: Optical micrograph of high tempered sample (heated to $1040{ }^{\circ} \mathrm{C}$, water quenched and re-heated to $550{ }^{\circ} \mathrm{C}$ ) showing the precipitated carbide (blackish) at the grain boundaries and in the grain of austenite matrix (grayish)

austenite with manganese and carbon that resulted in development of manganese carbide $\left(\mathrm{Mn}_{3} \mathrm{C}\right)$ along grain boundaries (Prabhudev, 1988). In water-quenched condition the rapid cooling throughout the entire section thickness prevents the saturation of austenite with manganese and carbon and consequently discourages the development of carbides (Plate 3). Hence, there is reasonably homogeneity of austenite with respect to carbon and manganese, and there is no favourable condition for the development of manganese carbide $\left(\mathrm{Mn}_{3} \mathrm{C}\right)$ along the grain boundaries. This probably explains the reason for the formation of the observed fully austenitic structure that is virtually free of carbides (Plate 3).

In martempering condition, the usual transformation of austenite to martensitic structure is suppressed because of high manganese content in the austenitic manganese steel (Table 1) and rapid quenching in salt bath from $1040^{\circ} \mathrm{C}$. The rapid cooling in a salt bath at a temperature of $250^{\circ} \mathrm{C}$ also prevents the development of carbides (Plate 4). The rapid cooling in salt bath at a temperature of $250^{\circ} \mathrm{C}$ like in water-quenched also prevents the saturation of austenite with manganese and carbon, and hence prevents the development of carbides along the grain boundaries. Holding at this temperature until the temperature of the whole section thickness is constant at $250^{\circ} \mathrm{C}$ in addition, decreases the overall thermal gradient thereby reducing the residual stresses associated with heat treatment operations (Rajan, et al, 1999). This may have explained its superior toughness compared to water-quenched sample (Table 2).

However, by re-heating the quenched samples, that is, subjecting the hardened austenitic manganese steel to tempering operation, carbide precipitation is induced at the grain boundaries and in the grains (Plate 5 - 7). During the reheating operation, carbon and manganese precipitate out along the austenite grain boundaries and within the austenite matrix (Prabhudev, 1988). The volume of this precipitation however increases with tempering temperature (Plate $5-7$ ). Hence, when slowly cooled in air the precipitated carbon and manganese saturate austenite grain boundaries and matrix, and precipitated out as manganese carbide, $\mathrm{Mn}_{3} \mathrm{C}$ (Perry et al, 1997).

It is observed from the outcome of the results

114 Journal of Science and Technology, Vol. 29, No. 2, Aug., 2009 
that in as-cast condition ASTM A 128 grade B4 is harder $(215 \mathrm{HB})$ than in water-quenched (209HB) and martempering (201HB) conditions. This may be due to the presence of carbide along the austenite grain boundaries of the as-cast sample (Plate 1). This may also explain its inferior toughness (117J) when compared with martempered (138J) and water-quenched (134J) conditions.

As noted earlier, water-quenched and martempered samples do not have carbides precipitates at the grain boundaries (Plate 3 and 4). However, the high hardness (Table 2) exhibited in water-quenched condition as compared to martempered may be attributed to well defined austenite grain boundaries in the microstructure of water-quenched samples (Plate 3) which have almost disappeared in the microstructure of martempered samples (Plate 4).Holding the matempered samples in salt bath until the temperature of the whole section thickness is constant at $250^{\circ} \mathrm{C}$ also decreases the overall thermal gradient thereby reducing the residual stresses associated with heat treatment operations and hence reduction in hardness.

In tempered conditions, the hardness values (228HB-245HB) are higher than in waterquenched condition $(215 \mathrm{HB})$. The reason may be due to the presence of carbide both at the austenite grain boundaries and in the matrix as seen in the microstructure of tempered sample (Plate 5 - 7). The hardness in tempered condition, however, increases with tempering temperature $\left(250^{\circ} \mathrm{C} / 228 \mathrm{HB}, 450^{\circ} \mathrm{C} / 241 \mathrm{HB}\right.$ and $\left.550^{\circ} \mathrm{C} / 245 \mathrm{HB}\right)$. The reason for this can be adduced to increase in volume fraction of carbides as the tempering temperature increases as shown in microstructure of tempered samples (Plate 5 - 7).

In water-quenched and martempered conditions, the absence of carbides improves the impact strength. However, this is more pronounced in martempered condition (138J) than in water-quenched condition (134J) because residual stresses associated with heat treatment operation have been reduced in the former. In the as-cast and tempered conditions however, the presence of carbides at grain boundaries and in the grains makes the castings to be very hard with characteristic low toughness. The impact strength is also noted to be decreasing with increasing tempering temperature (Table 2 ). This may be attributed to the observed increase in the volume fraction of carbides as the tempering temperature increases. This however, favours increase in hardness and decrease in the ductility and consequently, low impact strength.

Two of the opposing mechanical properties, hardness and impact strength, are reasonably exhibited simultaneously in the water-quenched and martempered conditions compared to other heat treatment procedures conducted. Therefore these two heat treatment procedures fairly represent post-casting processes suitable for ASTM A 128 grade B-4 steel components designed to function under a condition in which two properties, toughness and hardness are simultaneously required at a reasonable level. In spite of higher tensile strength and hardness of components produced from as-cast and tempered ASTM A 128 grade B-4 steel, they are susceptible to embrittlement. This susceptibility to embrittlement can therefore lead to early failure by brittle fracture and consequently limit their sphere of engineering applications.

\section{CONCLUSION}

The presence of large carbides either at the grain boundaries or at both the grain boundaries and in the grain of ASTM A 128 grade B-4 austenitic manganese steel affects its unique resistance to impact and abrasion wears. Its wear resistance becomes high but very susceptible to earlier brittle fracture under an impact and abrasive wear condition.

Tempering a hardened austenitic manganese steels promotes precipitation of carbides at the grain boundaries and in the grains. The volume fraction of these carbides also increases with tempering temperature.

In quench hardened and martempered conditions, austenitic manganese steel is free of carbides both at the grain boundaries and in the 
grains. These make it a good post-casting treatment for ASTM A 128 Grade B4 components meant to work under a condition in which resistance to abrasive wear and impact loading are major issues. However, in martempering condition, austenitic manganese steels have better plastic flows attributed to decrease in overall thermal gradients and reduction in residual stresses associated with heat treatment operation. This gives it a better combination of hardness and toughness than when it is in water quenched condition. Consequently, martempering is considered a better post-casting treatment for cast austenitic manganese steel ASTM A 128 Grade B4 components.

\section{REFERENCES}

ASTM A128/A128M-93 (2007) Standard Specification for Steel Castings and Austenitic Manganese Steel. p1

Avery, H.S. (1995). The Nature of Abrasion Wear, SAE Preprint 750822, Society of Automotive Engineers, Off-Highway Vehicle Meeting, Milwaukee: p2.

Bayraktar, E., Levaillant, C., and Altinta, S. (1994). Formability characterization of Hadfield steel, J. of Materials Processing Technology, 47(1-2): pp13-31.

BSI BS 10002-1 (2001). Metallic Materials Tensile Testing - Part 1: Test at Ambient Temperature.

García, A., Varela, A., García, L., Río, M.C., Naya, S. and Suárez, M. (2005). Comparing the Tribological Behaviour of an Austenitic Steel Subjected to Diverse Thermal Treatments, Wear, 258(1-4): pp 203-207.

Gavriljuk, V.G., Tyshchenko, A.I., Razumov, O.N., Petrov, Yu.N., Shanina, B.D. and Berns, H. (2006). Corrosion-Resistant Analogue of Hadfield Steel, Materials Science and Engineering: A, 420(1-2): pp 47-54.

He, L., Jin, Z., Lu, J. and Tang, J. (2002). Modulated Structures of $\mathrm{Fe}-10 \mathrm{Mn}-2 \mathrm{Cr}-$ 1.5C Alloy, Materials \& Design, 23(8): pp
717-720.

John, T. A. and Cornog, D. G. (1997). Sputtered Austenitic Manganese Steel, Thin Solid Films, 45(2): pp397-406.

Klueh, R. L. and Maziasz, P. J. (1990). Tensile and Microstructural Behavior of SoluteModified Manganese-Stabilized Austenitic Steels, Materials Science and Engineering A, 127(1): pp17-31.

Kuc, D., Niewielskia , G. and Cwajnaa, J. (2006). Influence of Deformation Parameters and Initial Grain Size on the Microstructure of Austenitic Steels after HotWorking Processes, Materials Characterization, 56(4-5): pp318-324.

Miyahara, K., Bae D. and Shimoidec, Y. (1994). Improvement of High Temperature Strength and Low Temperature Toughness of High Manganese-Chromium Austenitic Steels, Journal of Nuclear Materials, 212215(1): pp766-771.

Owen, W. S. and Grujicic, M. (1998). Strain Aging of Austenitic Hadfield Manganese Steel, Acta Materialia , 47(1): pp111-126.

Pelletier, J. M., Oucherif, F., Sallamand, P. and Vannes, A. B. (1995). Hadfield Steel Coatings on Low Carbon Steel by Laser Cladding, Materials Science and Engineering A, 202(1-2): pp142-147.

Perry, R.H. and Green, D.W. (1997). Chemical Engineers' Handbbok, McGraw-Hill, New York: p55

Peter, W.F. (1980). Steel Casting Handbook, Steel Founders' Society of America, New York: pp 1- 60.

Prabhudev, K.H. (1988). Handbook of Heat Treatment of Steels, Tata McGraw-Hill, New Delhi: pp762-763.

Rajan, T.V., Sharma, C.P. and Sharma, A. (1999). Heat Treatment Principles and Techniques, Prentice-Hall, New Delhi: pp448-249.

Rittel, D. and Roman, I. (1989). Tensile Deformation of Coarse-Grained Cast Austenitic

116 Journal of Science and Technology, Vol. 29, No. 2, Aug., 2009 
Manganese Steels, Materials Science and Engineering A, 110: pp77-87.

Smith, R.W. DeMonte, A. and Mackay, W.B.F. (2004). Development of High-Manganese Steels for Heavy Duty Cast-to-Shape Applications, J. of Materials Processing Technology: 153-154, pp589-595.

Subramanyan, D.K., Swansiger, A.E., and Avery, H.S. (1990). Austenitic Manganese Steels, ASM Handbook 1, New York: pp821-837.

Takahashia, H., Shindoa, Y., Kinoshitaa, H., Shibayamaa, T., Ishiyamab, S., Fukayab, K., Etob, M., Kusuhashic, M., Hatakeyamac, T. and Satoc, I. (1998). Mechanical Properties and Damage Behavior of Non-Magnetic High Manganese Austenitic Steels, J. of Nuclear Materials, 258-263(2): pp1644-1650.

Wang, T.S., Lu B., Zhang, M., Hou, R.J. and Zhang, F.C. (2007). Nanocrystallization and $\alpha$ Martensite Formation in the Surface Layer of Medium-Manganese Austenitic Wear-Resistant Steel Caused by Shot
Peening, Materials Science and Engineering: A, 458(1-2): pp249-252..

Wieser, P.F. (1980). Steel Casting Handbook, $5^{\text {th }}$ ed., Steel Founders' Society of America, Ohio: pp16-11 - 17-3

Zhang, F., Lv B., Hu B. and Li, Y. (2007). Flash Butt Welding of High Manganese Steel Crossing and Carbon Steel Rail, Materials Science and Engineering: A, pp454455: 288-292.

Zhang, G., Xing, J. and Gao, Y. (1998). Impact Wear Resistance of WC/Hadfield Steel Composite and Its Interfacial Characteristics, Wear, 260(7-8): pp728-734. 